\title{
Profesor Emerito Ingeniero Eduardo E. BAGLIETTO.
}

Elève de l'Université de Buenois Aires, il recevait son diplöme en 1920 comme Ingénieur Civil, avec Mention d'Honneur.

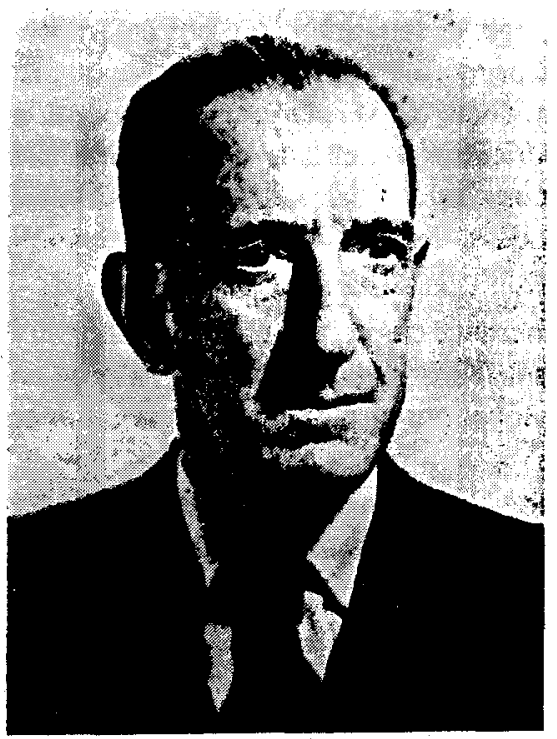

Chef de Travaux Pratiques en Géodésie, dés 1921 a la "Facultad de Ingenieria", il fut nommé Professeur Titulaire en 1930.

En 1962 il fut désigné Professeur Emérite.

Il était aussi Professeur de Géodésie à la "Escuela Superior Técnica del Ejército".

II fit des études spéciales en Europe en 1927-1928 : au Bureau International des Poids et Mesures, Breteuil : au Bureau de l'Heure de l'Observatoire de Paris, à I'Institut de Géodésie de Potsdam et aux Universités de Padoue, Milan, Rome. Turin et Naples.

En 1951 il fut nommé Directeur de I'Instituto de Geodesia" et le resta jusqu'en 1971 où il devint Directeur Honoraire. De 1961 à 1963 il a été membre de la "Comision Directiva de la Sociedad cientifica Argentine" et en 1971 il fut élu Membre Titulaire à I"Academia Argentina de la Ingenieria".

II a organisé et souvent dirigé de nombreux travaux à caractère national ou international :

- campagnes géodésiques aux Andes;

- campagnes gravimétriques depuis le sommet des Andes jusqu'au fond de la mer :

- liaisons gravimétriques internationales avec l'Angleterre, I'Italie, l'Espagne, l'Afrique du Sud.

II représentait régulièrement depuis 1948 I'Université de Buenos Aires aux assemblées générales de l'Association Internationale de Géodésie et faisait partie des Groupes spéciaux d'études 4.05 et 5.29.

II fut également l'auteur de nombreuses notes et communications dans les domaines de la Géodésie et de la Gravimétrie. 